\title{
Detection of altered acrosomal physiology of cryopreserved human spermatozoa after sperm residence in the female reproductive tract
}

\author{
E. Z. Drobnis ${ }^{1,2^{*}}$, P. R. Clisham ${ }^{1}$, C. K. Brazil ${ }^{1}$, L. W. Wisner ${ }^{1}$, \\ C. Q. Zhong ${ }^{1}$ and J. W. Overstreet ${ }^{1}$ \\ ${ }^{1}$ Division of Reproductive Biology and Medicine, Department of Obstetrics and Gynecology, School of \\ Medicine, and ${ }^{2}$ Department of Reproduction, School of Veterinary Medicine, University of California, \\ Davis, CA 95616-8659, USA
}

\begin{abstract}
At least some of the spermatozoa that remain motile following cryopreservation have sustained sublethal damage that reduces their functional capacity in vivo. Although it is believed that acrosomal damage is partly responsible for impaired sperm function in vivo, direct evidence for this hypothesis is lacking because spermatozoa have not been collected from the female reproductive tract for evaluation. In the study reported here, cervical mucus was collected from women $24 \mathrm{~h}$ after artificial insemination by cervical cup. For both cryopreserved and nonfrozen inseminates, spermatozoa within the cervical mucus and spermatozoa that migrated out of mucus into culture medium $(t=1 \mathrm{~h})$ were viable and had intact acrosomes. However, although nonfrozen spermatozoa did not initially respond to induction of the acrosome reaction with follicular fluid, a significant proportion of cryopreserved spermatozoa did respond. These results demonstrate that cryopreservation increases the acrosomal lability of spermatozoa residing in the female reproductive tract. An in vitro test was developed to detect this form of cryodamage. Sperm-free mucus was collected before insemination and spermatozoa from the inseminate were allowed to swim into this column of mucus in vitro. Spermatozoa recovered from this mucus sample were compared with spermatozoa from the paired sample collected from the cervix $24 \mathrm{~h}$ later. This in vitro test could detect acrosomal lability in cryopreserved semen samples, and this approach may prove valuable for studying sublethal cryodamage to the acrosome.
\end{abstract}

\section{Introduction}

Extensive research on cryopreservation has been carried out with spermatozoa from many species over the last forty years. Nevertheless, conception rates following artificial insemination with cryopreserved spermatozoa are lower than those obtained using nonfrozen spermatozoa, even when equal numbers of motile spermatozoa are inseminated. The lower fertility of cryopreserved spermatozoa suggests that those that survive freezing and remain motile after thawing have impaired functional competence in vivo. It is possible that all of the spermatozoa have reduced function, or that the size of the functional population is reduced. In general, it is agreed that at least part of this impaired function is due to abnormal sperm transport in the female reproductive tract, including decreased longevity of spermatozoa following insemination (Saacke, 1982; Hawk, 1987). Several lines of evidence support this hypothesis (1) longevity during incubation in vitro is reduced for cryopreserved spermatozoa (Saacke and White, 1972; Keel and Black, 1980; Critser et al., 1987b); (2) transport to the oviduct of motile, cryopreserved spermatozoa has been shown to be

*Correspondence.

Received 6 November 1992. impaired in some species (Mattner et al., 1969; Lightfoot and Salamon 1970; Lineweaver et al., 1970; Pursel et al., 1978; Saacke, 1982); (3) longevity or retention of cryopreserved spermatozoa in the female reproductive tract is reduced (Mattner et al., 1969; Pursel et al., 1978; Saacke, 1982; Parrish and Foote, 1986); and (4) conception rates achieved with cryopreserved spermatozoa can approach those for nonfrozen spermatozoa if insemination is more carefully timed with respect to ovulation (Smith et al., 1981; Parrish and Foote, 1986) or spermatozoa are inseminated closer to the oviduct (Lightfoot and Salamon, 1970; Byrd et al., 1990).

The sublethal cryodamage that results in abnormal sperm function has proved difficult to detect in vitro. The lack of laboratory methodology for detecting sperm cryodamage has been an impediment to studies of sperm cryobiology. Without good experimental endpoints, it is difficult to determine the mechanisms underlying diminished sperm function, and it is difficult to develop improved techniques of sperm cryopreservation. Endpoints such as embryonic development and rate of cell division that are useful for studying cryobiology in other cellular systems are not applicable to spermatozoa. Assessment of viability alone is useful for monitoring cryodamage in many cells, but this approach cannot detect the sublethal changes that can disrupt the highly complex function of mammalian 
spermatozoa. At the present time, the only effective measurement of sperm function in vivo is the conception rate following insemination (Amann, 1989). With the exception of dairy cattle, this approach cannot be used for initial testing of cryopreservation methods. In vitro assays of sperm function are required for preliminary studies to identify methods for testing in clinical trials.

Cryopreserved spermatozoa have been shown to differ from nonfrozen spermatozoa by several laboratory criteria (references are examples for human spermatozoa), including the ultrastructure (Woolley and Richardson, 1978), percentage of motile spermatozoa (Critser et al., 1987b), swimming velocity (Pilikian et al., 1982), metabolism (Ackerman and Behrman, 1975), percentage of intact acrosomes (Pilikian and Guerin, 1986; Critser et al., 1987a; Centola et al., 1990), acrosomal enzymes (Mack and Zaneveld, 1987), acrosomal function (Cross and Hanks, 1991), longevity (Critser et al., $1987 \mathrm{~b}$ ), penetration of cervical mucus (Ulstein, 1973), binding to the zona pellucida (Coddington et al., 1991), and fusion with zona-free hamster oocytes (Critser et al., 1987b). However, the relationship of these measures to sperm function in the female reproductive tract is not well understood. In human semen, distinct subpopulations of spermatozoa can be distinguished on the basis of physiological characteristics (e.g. Davis and Katz, 1988; Robertson et al., 1988; Mortimer and Camenzind, 1989; Menkveld et al., 1991). Measurements that provide mean values for the entire population of spermatozoa in semen may not detect differences in the subpopulations of spermatozoa that are biologically important. Assays that do not distinguish between motile and immotile spermatozoa may be particularly insensitive for detecting changes in spermatozoa that are functionally significant. In vitro tests for sperm cryodamage must be carefully chosen to approximate conditions encountered by the fertilizing spermatozoon in vivo. The standard assays of sperm longevity may detect an increased sensitivity of cryopreserved spermatozoa to conditions in vitro (e.g. $\mathrm{pH}$, toxic components of seminal plasma), but these conditions may have little relevance to the environment of the female reproductive tract.

In the experiments reported here, we have studied the motility and acrosomal status of cryopreserved human spermatozoa following a period of residence in the female reproductive tract. Such spermatozoa can be sampled noninvasively from the cervical canal, and they represent a population that is similar to that evaluated clinically in the post-coital test (Hanson et al., 1982). The physiology of nonfrozen spermatozoa recovered from cervical mucus has been studied in some detail. These cervical spermatozoa remain motile, acrosome intact, and capable of fertilizing oocytes for at least three days after insemination (Gould et al., 1984; Zinaman et al., 1989). These properties of cervical spermatozoa are consistent with prolonged functional integrity and with the hypothesis that the cervix is a reservoir for spermatozoa that can eventually participate in fertilization. In this communication, we report observations of abnormal acrosomal physiology of cryopreserved spermatozoa recovered from the cervix, and we describe an in vitro assay of sperm-cervical mucus interaction that may be useful for predicting this altered physiology of cryodamaged human spermatozoa.

\section{Materials and Methods}

\section{Preparation of cryopreserved and fresh semen for insemination}

The six research subjects who provided semen for this study were donors in the therapeutic artificial insemination programme. After approval was obtained from the University of California, Davis Institutional Review Board, informed consent was obtained to use these samples for this research. Each donor was screened to exclude genetic and health problems as recommended by the American Fertility Society (1990), and they were further screened for good semen quality and sperm cryosurvival. Cryopreserved semen from these donors was proven to be fertile in the artificial insemination programme.

The cryopreservative diluent was modified from the TESTyolk medium of Bolanos et al. (1983). All reagents used were obtained from Sigma Chemical Company (St Louis, MO). The

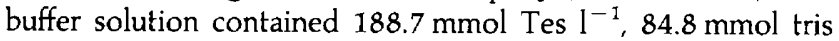
base $\mathrm{l}^{-1}$, $11.1 \mathrm{mmol}$ glucose $1^{-1}, 15 \mathrm{iu}$ penicillin $\mathrm{Gml}^{-1}$ (sodium salt), and 25 iu streptomycin sulfate $\mathrm{ml}^{-1}$ in HPLCgrade water. Complete diluent was prepared by combining $80 \%$ (v/v) buffer solution and $20 \%$ fresh egg yolk. The yolk granules were sedimented by centrifuging the diluent at $1000 \mathrm{~g}$ for $30 \mathrm{~min}$. Approximately the upper two-thirds of the supernatant solution was collected, and the $\mathrm{pH}$ was adjusted to 7.40 with $1.0 \mathrm{~mol} \mathrm{NaOH} \mathrm{l}{ }^{-1}$. After filtering the diluent through a sterile, $0.45 \mu \mathrm{m}$ pore-size filter, $10 \mathrm{ml}$ aliquots of diluent were frozen in $15 \mathrm{ml}$ centrifuge tubes (Corning Glass Works, NY) and stored at $-20^{\circ} \mathrm{C}$. The diluent was thawed and warmed above $20^{\circ} \mathrm{C}$ before use.

Semen was collected by masturbation and was allowed to liquify at room temperature. After liquefaction, the volume was measured and the concentration and percentage of motile spermatozoa in the semen were determined. For semen to be cryopreserved, the total number of motile spermatozoa in the ejaculate was calculated. Sperm 'freezability' was defined as the ratio of the percentage of motile spermatozoa after thawing to the percentage of motile spermatozoa in the fresh ejaculate. For each donor, the mean sperm freezability for the three previous ejaculates was used to estimate motility loss during cryopreservation, and the semen was diluted to produce a predicted after thawing insemination dose of $30 \times 10^{6}$ motile spermatozoa in $0.5 \mathrm{ml}$. If the motile sperm density was inadequate to dilute at least $1: 1$ with diluent, the specimen was not used. Glycerol was added in three aliquots over $30 \mathrm{~min}$ to a final $5 \%(\mathrm{v} / \mathrm{v})$ concen tration. After the final addition of glycerol, the semen was mixed thoroughly by gentle inversion, and $0.5 \mathrm{ml}$ aliquots were pipetted into $1.2 \mathrm{ml}$, internal thread, screw-top cryovials (Corning Glass Works). Cryovials were attached to canes and loaded into a programmable freezer equipped with a cane rack (CryoMed 1010, CryoMed, New Baltimore, MI). The cooling programme produced an intra-vial cooling rate of $1^{\circ} \mathrm{C} \mathrm{min}^{-1}$ to $4^{\circ} \mathrm{C}$ and $10^{\circ} \mathrm{C} \mathrm{min}^{-1}$ to $-100^{\circ} \mathrm{C}$. Once the intra-vial temperature stabilized at $-100^{\circ} \mathrm{C}$, the freezing chamber was opened and the canes were quickly transferred to liquid nitrogen. Cryopreserved semen was stored in liquid nitrogen for at least six months before use.

Semen was thawed by transferring individual cryovials rapidly to a thawing thermos (Continental Plastics, Baraboo, WI) containing water at $37^{\circ} \mathrm{C}$. After $5 \mathrm{~min}$, the cryovial was 
transferred to room temperature and dried carefully before opening. Diluent, $0.5 \mathrm{ml}$, was added to produce $1 \mathrm{ml}$ of cryopreserved semen for insemination.

\section{Insemination and collection of cervical mucus}

Informed consent to obtain mucus samples for this study was obtained from patients undergoing therapeutic donor insemination. Artificial insemination was performed using a cervical cup as described previously (Hanson and Overstreet, 1981). Twenty-four women were inseminated with cryopreserved spermatozoa and nine were inseminated with nonfrozen spermatozoa from the same donors. Each patient was studied in a single experiment. Patients were instructed to abstain from sexual intercourse for 2-3 days before insemination and 2-3 days after insemination. Ovulation was detected using a home testing kit for urinary LH (Ovuquick; Monoclonal Antibodies, Inc., Sunnyvale, CA). A single insemination was performed on the day that the $\mathrm{LH}$ rise was detected. Before placing the cervical cup, 25-50 $\mu \mathrm{l}$ of cervical mucus was collected from the cervical canal (Katz et al., 1980) for use in the in vitro assay described below. Either liquified, nonfrozen semen or thawed, cryopreserved semen was drawn into a polyethylene catheter attached to a $3 \mathrm{ml}$ syringe. A small aliquot (approximately $50 \mu \mathrm{l}$ ) of the semen was used for the in vitro assay described below. After placement of the cervical cup, at least $1.5 \mathrm{ml}$ of nonfrozen semen or $1.0 \mathrm{ml}$ of cryopreserved semen was used for insemination. The cup was left in place for $4-6 \mathrm{~h}$ and was removed by the patient. The day after insemination (16-24 h), $25-50 \mu \mathrm{l}$ of mucus was collected as described previously and used for recovery of cervical spermatozoa.

\section{Evaluation of the acrosomal status of cervical spermatozoa}

The procedures for evaluation of spermatozoa in cervical mucus, recovery of spermatozoa from cervical mucus and evaluation of sperm acrosomal status have been described in detail by Zinaman et al. (1989). Briefly, a 10-20 $\mu \mathrm{l}$ aliquot of mucus was incubated in I $\mu \mathrm{g}$ Hoescht $33258 \mathrm{ml}^{-1}$ (H258; Sigma) in Dulbecco's phosphate-buffered saline (DPBS, $\mathrm{pH} \mathrm{7.40)}$ ) at $37^{\circ} \mathrm{C}$ for $10 \mathrm{~min}$ to evaluate the viability of cervical spermatozoa. The mucus was recovered with forceps, rinsed with $2 \mathrm{ml}$ warm DPBS while supported on nylon mesh, and transferred to a microscope slide. A smear was then made and the slide was transferred to a slide jar containing $100 \%$ ethanol at $-20^{\circ} \mathrm{C}$. After at least $\mathrm{I} \mathrm{h}$, the slide was air-dried, and the mucus smear was treated with $100 \mu \mathrm{g}$ fluoresceinated Pisum sativum lectin $\mathrm{ml}^{-1}$ (FITC-PSA; Vector Laboratories, Burlingame, CA) in DPBS for $10 \mathrm{~min}$. The slide was rinsed in deionized water and dehydrated in $100 \%$ ethanol for at least $1 \mathrm{~h}$. Slides were mounted with a minimal volume of ethanol containing $100 \mathrm{mg}$ 1,4-diazabicyclo [2.2.2] octane $\mathrm{ml}^{-1}$ (DABCO; Sigma) and the slide preparation was sealed with nail enamel. These observations were made only on cryopreserved spermatozoa.

Spermatozoa were recovered from cervical mucus by emptying the remaining mucus from the catheter into $400 \mu \mathrm{l}$ of BWW medium as modified by Overstreet et al. (1980). The mucus was observed under a stereomicroscope with the mirror adjusted to produce a dark background. If spermatozoa were present, they could be seen as small, refractile points, migrating within the mucus. Only motile spermatozoa migrate out of the mucus (authors' unpublished observation), and spermatozoa have never been observed re-entering the mucus under these conditions. After incubation for $60 \mathrm{~min}\left(37^{\circ} \mathrm{C}, 5 \% \mathrm{CO}_{2}\right.$ in water-saturated air), the mucus was removed and evaluated as described for the freshly collected mucus. The suspension containing spermatozoa that migrated out of mucus was evaluated for acrosomal status immediately $(t=1 \mathrm{~h})$ and after a further $5 \mathrm{~h}$ incubation $(t=6 \mathrm{~h})$. Spermatozoa were evaluated for spontaneous acrosome reactions and for acrosome reactions induced with human follicular fluid.

The human follicular fluid used in this study was collected from a single patient undergoing follicular aspiration before in vitro fertilization. After the oocytes were removed, follicular aspirates were frozen and stored at $-20^{\circ} \mathrm{C}$ until use. This batch of follicular fluid was screened for bioactivity as described by Zinaman et al. (1989). Just before use, follicular fluid was thawed and microfuged for $60 \mathrm{~s}$ to sediment any particulate material. The supernatant was used immediately.

The sperm suspension recovered from cervical mucus was mixed gently before removing two $80 \mu$ l test samples. Twenty microlitres of human follicular fluid was added to the first sample to induce acrosome reactions, and $20 \mu \mathrm{l}$ BWW was added to the second sample as a control treatment (spontaneous acrosome reactions). One microlitre of $\mathrm{H} 258\left(100 \mu \mathrm{g} \mathrm{ml}^{-1}\right.$ deionized water) was added after incubation for $5 \mathrm{~min}$. After incubation for a total of $15 \mathrm{~min}$, the spermatozoa were fixed by adding $100 \mu \mathrm{l}$ of $2 \%$ paraformaldehyde in DPBS. Ten minutes later, the spermatozoa were collected on polycarbonate filters and stained with FITC-PSA. The filters were transferred to slides, then mounted and sealed as described for mucus.

In each sample, one hundred spermatozoa were examined with appropriate epifluorescence microscopy. Individual spermatozoa were considered viable if they excluded the DNA stain H258. They were considered acrosome reacted if they were viable and did not label with FITC-PSA over the acrosomal cap region (Cross et al., 1986). The percentage of acrosome-reacted spermatozoa was calculated as the quotient of the number of acrosome-reacted spermatozoa and the total number of viable spermatozoa.

\section{Selection of spermatozoa by penetration of cervical mucus in vitro}

The methods used for recovery and evaluation of spermatozoa after penetration of cervical mucus in vitro were the same as those described by Zinaman et al. (1989), except that in these experiments the in vitro and in vivo experiments were paired. That is, the in vitro test was carried out with mucus that was obtained from the patient just before insemination and with a small aliquot of the inseminate. Of twenty-four patients inseminated with cryopreserved spermatozoa, paired samples were obtained for thirteen experiments. After the mucus was examined to ensure that it did not contain spermatozoa, both ends of the collection catheter were sealed with tube sealer (Seal-ease; Clay Adams, Parsippany, NJ) and the catheter was cut in half. The cut ends of the catheter were positioned such that the mucus was in contact with $50 \mu \mathrm{l}$ of semen contained in a $1.5 \mathrm{ml}$ cryovial. The cryovial and catheters were incubated in a $17 \times 100 \mathrm{~mm}$ culture tube (Falcon) for $\mathrm{I} \mathrm{h}$. After incubation, 
Table 1. Acrosomal response of nonfrozen and cryopreserved human spermatozoa to follicular fluid after recovery from cervical mucus and incubation for $1 \mathrm{~h}$ and $6 \mathrm{~h}$ in vitro

\begin{tabular}{|c|c|c|c|c|c|}
\hline \multirow[b]{3}{*}{$\begin{array}{l}\text { Sperm } \\
\text { treatment }\end{array}$} & \multirow[b]{3}{*}{$\begin{array}{l}\text { Number of } \\
\text { experiments }\end{array}$} & \multicolumn{4}{|c|}{ Percentage of acrosome-reacted spermatozoa } \\
\hline & & \multicolumn{2}{|c|}{ I $h$ incubation } & \multicolumn{2}{|c|}{$6 \mathrm{~h}$ incubation } \\
\hline & & $\begin{array}{l}\text { BWW } \\
\text { control }\end{array}$ & $\begin{array}{l}\text { Follicular } \\
\text { fluid }\end{array}$ & $\begin{array}{l}\text { BWW } \\
\text { control }\end{array}$ & $\begin{array}{c}\text { Follicular } \\
\text { fluid }\end{array}$ \\
\hline Nonfrozen & 9 & $1 \pm 0$ & $2 \pm 1$ & $4 \pm 1$ & $17 \pm 3$ \\
\hline Cryopreserved & 24 & $3 \pm 1$ & $7^{*} \pm 1$ & $8 \pm 2$ & $19 \pm 3$ \\
\hline
\end{tabular}

Data are presented as means \pm SEM where experiment is the experimental unit. One hundred spermatozoa were scored in each experiment. Spermatozoa were considered to be acrosome reacted if they excluded the supravital dye Hoescht 33258 and had no evidence of acrosomal cap staining with the fluoresceinated pea lectin FITCPSA. BWW: BWW culture medium as modified by Overstreet et al. (1980).

*Cryopreserved spermatozoa were significantly different $(P<0.0001)$ from nonfrozen spermatozoa.

the catheters were removed from the semen, the ends were rinsed with 1-2 $\mathrm{ml} B W W$, and $5 \mathrm{~mm}$ was cut from the rinsed ends of the catheter to remove any spermatozoa adhering to the mucus surface. The mucus in these catheters was then recovered and evaluated in the same manner as mucus collected after insemination.

\section{Statistical analysis}

Differences between nonfrozen and cryopreserved spermatozoa were detected using general linear model analysis of variance with sperm treatment as a fixed factor. Spermatozoa that penetrated mucus in vitro were compared with spermatozoa recovered from the cervical mucus after insemination by paired $t$ test.

\section{Results}

Viability and acrosomal status of cryopreserved spermatozoa in cervical mucus

The viability of cryopreserved spermatozoa in the cervical mucus was high and the incidence of acrosome reactions was low. In the fourteen samples of cervical mucus collected on the day after insemination, the viability was $91 \pm 2 \%$ and the percentage of viable, acrosome-reacted spermatozoa was $0.1 \pm 0.3 \%$. These results are comparable to our previous observations on nonfrozen spermatozoa (Zinaman et al., 1989). Similarly, $4 \pm 1 \%$ of the spermatozoa remaining in the mucus after $1 \mathrm{~h}$ in BWW medium were acrosome reacted, which is also similar to our previous results for nonfrozen spermatozoa.

\section{Response of cryopreserved spermatozoa recovered from cervical mucus to induction of the acrosome reaction}

In nine experiments with nonfrozen spermatozoa, the acrosomal physiology of spermatozoa recovered from cervical mucus was similar to that observed in our previous study (Zinaman et al., 1989). That is, very few spermatozoa were acrosome reacted after migrating out of the mucus (Table 1 ), and, at this time $(t=1 \mathrm{~h})$, nonfrozen spermatozoa did not acrosome react in response to challenge with follicular fluid. After further incubation $(t=6 \mathrm{~h})$, the level of spontaneous acrosome reactions increased slightly, and a significant proportion of spermatozoa acrosome reacted in response to follicular fluid. Cryopreserved spermatozoa differed from this pattern in that a higher proportion of spermatozoa responded to follicular fluid immediately after migrating from the mucus (Table 1).

The response of cryopreserved spermatozoa to follicular fluid varied among experiments. For nonfrozen spermatozoa, the range of acrosome reactions in response to follicular fluid at $t=1 \mathrm{~h}$ was $0-5 \%$. This was also the case in our previous experiment with nonfrozen spermatozoa. The distribution of samples for this variable was bimodal such that about half of the samples fell within the normal and half had more acrosome reactions than normal. When the experiments with cryopreserved spermatozoa having a normal acrosomal response were grouped separately from experiments with large numbers of acrosome reactions, the spermatozoa from the latter experiments not only had a greater acrosomal response to follicular fluid at $t=1 \mathrm{~h}$, but also appeared to have more spontaneous acrosome reactions at this time (Table 2). The variation among donors in the response of cryopreserved spermatozoa to follicular fluid at $t=1 \mathrm{~h}$ was significant $(P<0.03$; data not shown). However, each of the six donors for whom multiple samples were analysed had normal acrosomal response to follicular fluid at $t=1 \mathrm{~h}$ in some experiments (1-5\% acrosomereacted spermatozoa) and higher responses in other experiments.

\section{Acrosomal response to follicular fluid of cryopreserved spermatozoa following mucus penetration in vitro}

In the thirteen experiments for which paired data were collected, there was no significant difference in acrosomal status between spermatozoa that penetrated cervical mucus in vitro and spermatozoa that were recovered from cervical mucus $24 \mathrm{~h}$ after insemination (Table 3). In eleven of thirteen experiments, the $t=1 \mathrm{~h}$ acrosomal response of spermatozoa to follicular fluid after mucus penetration in vitro was predictive of whether 
Table 2. Two groups of cryopreserved human spermatozoa having different responses to follicular fluid after recovery from cervical mucus and incubation for $1 \mathrm{~h}$ and $6 \mathrm{~h}$ in vitro

\begin{tabular}{|c|c|c|c|c|c|}
\hline \multirow[b]{3}{*}{$\begin{array}{l}\text { Acrosomal } \\
\text { response }\end{array}$} & \multirow[b]{3}{*}{$\begin{array}{l}\text { Number of } \\
\text { experiments }\end{array}$} & \multicolumn{4}{|c|}{ Percentage of acrosome-reacted spermatozoa } \\
\hline & & \multicolumn{2}{|c|}{$1 \mathrm{~h}$ incubation } & \multicolumn{2}{|c|}{$6 \mathrm{~h}$ incubation } \\
\hline & & $\begin{array}{c}\text { BWW } \\
\text { control }\end{array}$ & $\begin{array}{l}\text { Follicular } \\
\text { fluid }\end{array}$ & $\begin{array}{l}\text { BWW } \\
\text { control }\end{array}$ & $\begin{array}{l}\text { Follicular } \\
\text { fluid }\end{array}$ \\
\hline Normal & 13 & $2 \pm 0$ & $3 \pm 1$ & $6 \pm 2$ & $17 \pm 5$ \\
\hline Increased & 11 & $4 \pm 1$ & $11 \pm 1$ & $10 \pm 3$ & $21 \pm 4$ \\
\hline
\end{tabular}

Data are presented as means \pm SEM where experiment is the experimental unit. One hundred spermatozoa were scored in each experiment. Spermatozoa were considered to be acrosome reacted if they excluded the supravital dye Hoescht 33258 and had no evidence of acrosomal cap staining with the fluoresceinated pea lectin FITC-PSA. BWW: BWW culture medium as modified by Overstreet et al. (1980). Spermatozoa in a given experiment were considered to have increased responsiveness to follicular fluid if the percentage of acrosome reactions was $\geqslant 6 \%$ after follicular fluid challenge at the $1 \mathrm{~h}$ time point.

Table 3. Acrosomal response of cryopreserved human spermatozoa to follicular fluid after penetration of cervical mucus in vitro or after $24 \mathrm{~h}$ in the female reproductive tract (in vivo assay)

\begin{tabular}{|c|c|c|c|c|}
\hline \multirow{3}{*}{$\begin{array}{l}\text { Source of } \\
\text { cervical } \\
\text { mucus }\end{array}$} & \multicolumn{4}{|c|}{ Percentage of acrosome-reacted spermatozoa } \\
\hline & \multicolumn{2}{|c|}{ I h incubation } & \multicolumn{2}{|c|}{$6 \mathrm{~h}$ incubation } \\
\hline & $\begin{array}{c}\text { BWW } \\
\text { control }\end{array}$ & $\begin{array}{l}\text { Follicular } \\
\text { fluid }\end{array}$ & $\begin{array}{l}\text { BWW } \\
\text { control }\end{array}$ & $\begin{array}{c}\text { Follicular } \\
\text { fluid }\end{array}$ \\
\hline In vitro & $2 \pm 1$ & $6 \pm 1$ & $6 \pm 2$ & $27 \pm 4$ \\
\hline In vivo & $3 \pm 1$ & $7 \pm 1$ & $9 \pm 2$ & $23 \pm 4$ \\
\hline
\end{tabular}

Data are presented as means \pm SEM for thirteen paired experiments. One hundred spermatozoa were scored for each treatment. There were no significant differences between in vitro and in vivo penetration. Spermatozoa were considered to be acrosome reacted if they excluded the supravital dye Hoescht 33258 and had no evidence of acrosomal cap staining with the fluoresceinated pea lectin FITC-PSA. BWW culture medium as modified by Overstreet $e t$ al. (1980). The in vitro assay was performed with a mucus sample collected just before insemination, and incubated with an aliquot of the semen used for the insemination. The in vivo assay was performed with mucus collected from the cervix $24 \mathrm{~h}$ after insemination.

the response for spermatozoa recovered from the cervix would be normal ( $\leqslant 5 \%$ acrosome reactions) or increased ( $\geqslant 6 \%$ acrosome reactions). In one case the response in vitro was normal $(4 \%)$ and the response in vivo was increased $(10 \%)$, whereas in a second case the response in vitro was increased $(9 \%)$ and the response in vivo was normal (5\%).

\section{Discussion}

In this study the physiology of a highly selected subpopulation of cryopreserved spermatozoa was evaluated. The semen samples used for insemination were obtained from men with high semen quality having spermatozoa relatively resistant to cryodamage. The spermatozoa were further selected for their ability to penetrate cervical mucus, remain viable in the cervix and subsequently migrate out of mucus. Although there is no direct evidence that these spermatozoa are representative of the fertilizing population, there is indirect evidence in a number of species that the cervix functions as a reservoir for spermatozoa (reviewed in Drobnis and Overstreet, 1992). Human spermatozoa that remain motile following cryopreservation have reduced ability to penetrate cervical mucus (Ulstein, 1973). This decreased function is probably due in part to inadequate sperm motility, but changes in the sperm surface are also likely to be involved. In addition to penetrating the cervical mucus, the spermatozoa that we recovered for study had also remained viable within the cervix for many hours and could migrate out of the cervical mucus into culture medium in vitro. A very high proportion of both cryopreserved and nonfrozen spermatozoa in the cervical mucus were viable and motile. Cryopreserved human spermatozoa have reduced longevity in vitro (Critser et al., 1987b), and they disappear from cervical mucus more rapidly than do nonfrozen spermatozoa (Overstreet and Drobnis, 1993), suggesting that nonmotile spermatozoa are preferentially lost from the cervix. The current model for sperm transport in the ruminant cervix (Mullins and Saacke, 1989) proposes that immotile spermatozoa are flushed from the cervix by mucus secretion, whereas motile spermatozoa are retained in the cervix because of their continued migration, which is oriented against the direction of mucus flow. If human sperm transport is consistent with this model, the cryopreserved spermatozoa retained in the cervix represent a subpopulation that maintain their motility during prolonged residence in the female reproductive tract. In light of the fact that the spermatozoa recovered from cervical mucus represent such a select subpopulation of cryopreserved spermatozoa, it is remarkable that they differed from nonfrozen spermatozoa in their physiology.

It has been suspected for more than twenty years that cryopreservation damages the sperm acrosome and that acrosomal damage results in decreased fertility. The proportion of spermatozoa in semen with intact acrosomes is well-correlated with conception rates after artificial insemination in cattle (Saacke and White, 1972), suggesting that motile spermatozoa in the inseminate with damaged acrosomes have reduced functional capacity in vivo. However, these studies used techniques 
involving sperm fixation that did not distinguish between motile and immotile spermatozoa. It is possible that the spermatozoa with abnormal acrosomes were dead, and that this form of lethal damage was merely coincident with other sublethal damage that was directly related to the abnormal function of the motile spermatozoa. This problem of interpretation applies generally to previous studies of cryopreservation damage to the acrosome. Our experiments which assess living, cryopreserved spermatozoa recovered from the human cervix provide the first direct evidence of abnormal acrosomal physiology in the population of highly motile, cryopreserved spermatozoa that remain viable in the female tract.

The increased incidence of acrosome reactions and the enhanced acrosomal response to follicular fluid are consistent with premature capacitation of cryopreserved spermatozoa. The acrosome reaction in the fertilizing spermatozoon is believed to occur in the vicinity of the oocyte (reviewed in Meizel, 1978, 1985; Yanagimachi, 1981, 1988; Talbot, 1985), and premature capacitation and acrosome reactions may be responsible for the decreased duration of normal function observed for cryopreserved spermatozoa. This hypothesis is supported by the observation that cryopreserved human spermatozoa have the ability to fuse with zona-free hamster oocytes immediately after separation from seminal plasma, and rapidly lose this ability during subsequent incubation (Critser $e$ t al., 1987b). In contrast, nonfrozen spermatozoa require several hours of preincubation to complete capacitation in vitro and they retain the ability to fuse with oocytes for many hours. Not only do premature acrosome reactions reduce sperm longevity, but untimely completion of this cellular event may inhibit transport of spermatozoa to the site of fertilization and normal interaction with the oocyte investments. For example, acrosome-reacted hamster spermatozoa have reduced ability to penetrate the cumulus oophorus (Suarez et al., 1984; Cherr et al., 1986; Cummins and Yanagimachi, 1986). It is generally believed, although not proven, that the fertilizing spermatozoon completes the acrosome reaction during interaction with the oocyte investments, and that spermatozoa that undergo the acrosome reaction outside the vicinity of the oocyte cannot participate in fertilization.

The in vitro assay used in this study measures the acrosomal physiology of the subpopulation of spermatozoa that can migrate through cervical mucus. The acrosomal physiology of cryopreserved spermatozoa, as evaluated with this assay, was similar to that of spermatozoa recovered from the cervix after insemination. In paired comparisons, the assay could predict subsequent abnormal acrosomal physiology of cryopreserved spermatozoa in vivo. This technique can be used to study sublethal cryodamage to spermatozoa and to compare various cryopreservation methods for their ability to reduce this form of damage to the sperm acrosome.

The authors thank $C . K$. Tollner for cryopreserving the semen used in these experiments. This study was supported by $\mathrm{NIH}$ Grant HD25907.

\section{References}

Ackerman DR and Behrman SJ (1975) Artificial insemination and preservation of human semen In Progress in Infertility pp 765 Eds SJ Behrman and RW Kister. Little Brown and Co., Boston
Amann RP (1989) Can the fertility potential of a seminal sample be predicted accurately? Journal of Andrology 10 89-98

American Fertility Society (1990) New guidelines for the use of semen donor insemination: 1990 Fertility and Sterility 53 (Supplement 1) 1S-13S

Bolanos JR, Overstreet JW and Katz DF (1983) Human sperm penetration of zona-free hamster eggs after storage of the semen for 48 hours at $2^{\circ}$ to $5^{\circ} \mathrm{C}$ Fertility and Sterility 39 536-541

Byrd W, Bradshaw K, Carr B, Edman C, Odom J and Ackerman G (1990) A prospective randomized study of pregnancy rates following intrauterine and intracervical insemination using frozen donor sperm Fertility and Sterility $\mathbf{5 3}$ $521-527$

Centola GM, Mattox JH, Burde S and Leary JF (1990) Assessment of the viability and acrosome status of fresh and frozen-thawed human spermatozoa using single-wavelength fluorescence microscopy Molecular Reproduction and Development 27 130-135

Cherr GN, Lambert H and Katz DF (1986) In vitro studies of the golden hamster sperm acrosome reaction: completion on the zona pellucida and induction by homologous soluble zonae pellucidae Developmental Biology 114 119-131

Coddington CC, Franken DR, Burkman LJ, Oosthuizen WT, Kruger T and Hodgen GD (1991) Functional aspects of human sperm binding to the zona pellucida using the hemizona assay Joumal of Andrology 12 1-8

Critser JK, Arneson BW, Aaker DV, Huse-Benda AR and Ball GD (1987a) Cryopreservation of human spermatozoa. II. Postthaw chronology of motility and of zona-free hamster ova penetration Fertility and Sterility 47 980-984

Critser JK, Huse-Benda AR, Aaker DV, Arneson BW and Ball GD (1987b) Cryopreservation of human spermatozoa. I. Effects of holding procedure and seeding on motility, fertilizability, and acrosome reaction Fertility and Sterility $47656-663$

Cross NL and Hanks SE (1991) Effects of cryopreservation on human sperm acrosomes Human Reproduction 6 1279-1283

Cross NL, Morales P, Overstreet JW and Hanson FW (1986) Two simple methods for detecting acrosome-reacted human sperm Gamete Research 15 213-226

Cummins JM and Yanagimachi R (1986) Development of ability to penetrate the cumulus oophorus by hamster spermatozoa capacitated in vitro in relation to the timing of the acrosome reaction Gamete Research 15 187-212

Davis RO and Katz DF (1988) Quantitative analysis of sperm motion kinematics from real-time video-edge images Proceedings of the International Society for Optical Engineering 832 14-20

Drobnis EZ and Overstreet JW (1992) Natural history of mammalian spermatozoa in the female reproductive tract Oxford Reviews of Reproductive Biology 14 1-45

Gould JE, Overstreet JW and Hanson FW (1984) Assessment of human sperm function after recovery from the female reproductive tract Biology of Reproduction $31888-894$

Hanson FW and Overstreet JW (1981) The interaction of human spermatozoa with cervical mucus in vivo American joumal of Obstetrics and Gynecology 140 173-179

Hanson FW, Overstreet JW and Katz DF (1982) A study of the relationship of motile sperm numbers in cervical mucus $\mathbf{4 8}$ hours after artificial insemination with subsequent fertility American Journal of Obstetrics and Gynecology 143 85-90

Hawk HW (1987) Transport and fate of spermatozoa after insemination of cattle Journal of Dairy Science 70 1487-1503

Katz DF, Overstreet JW and Hanson FW (1980) A new quantitative test for sperm penetration into cervical mucus Fertility and Sterility 33 171-186

Keel BA and Black JB (1980) Reduced motility longevity in thawed human spermatozoa Archives of Andrology 4 213-215

Lightfoot RJ and Salamon S (1970) Fertility of ram spermatozoa frozen by the pellet method Joumal of Reproduction and Fertility 22 385-398

Lineweaver JA, Hafez ESE, Ehlers MH, Dickson WM and King JR (1970) Sperm transport in cattle and gonadotropin-treated calves Comell Veterinarian 60 $372-382$

Mack SR and Zaneveld LJD (1987) Acrosomal enzymes and ultrastructure of unfrozen and cryotreated human spermatozoa Gamete Research 18 375-383

Mattner PE, Entwistle KW and Martin ICA (1969) Passage, survival and fertility of deep-frozen ram semen in the genital tract of the ewe Australian Journal of Biological Science 22 181-187

Meizel S (1978) The mammalian sperm acrosome reaction. A biochemical approach. In Development in Mammals pp 1-64 Ed. MH Johnson. NorthHolland, New York 
Meizel S (1985) Molecules that initiate or help stimulate the acrosome reaction by their interaction with the mammalian sperm surface American Journal of Anatomy 17 284-302

Menkveld R, Franken DR, Kruger TF, Oehninger S and Hodgen GD (1991) Sperm selection capacity of the human zona pellucida Molecular Reproduction and Development 30 346-352

Mortimer D and Camenzind AR (1989) The role of follicular fluid in inducing the acrosome reaction of human spermatozoa incubated in vitro Human Reproduction 4 169-174

Mullins KJ and Saacke RG (1989) Study of the functional anatomy of bovine cervical mucosa with special reference to mucus secretion and sperm transport Anatomical Record 225 106-117

Overstreet JW and Drobnis EZ (1993) Sperm transport in the female tract. In Advances in Donor Insemination pp 33-49 Eds CLR Barratt and ID Cooke. Cambridge University Press, Cambridge

Overstreet JW, Yanagimachi R, Katz DF, Hayashi K and Hanson FW (1980) Penetration of human spermatozoa into the human zona pellucida and the zona-free hamster egg: a study of fertile donors and infertile patients Fertility and Sterility 33 534-542

Parrish JJ and Foote RH (1986) Fertility of cooled and frozen rabbit sperm measured by competitive fertilization Biology of Reproduction 35 253-257

Pilikian S and Guerin JF (1986) Acrosome-reacting capacity of frozen-thawed human semen: relation to hamster ova penetration Archives of Andrology 16 209-214

Pilikian S, Czyba JC and Guerin JF (1982) Effects of various concentrations of glycerol on post-thaw motility and velocity of human spermatozoa Cryobiology 19 147-153

Pursel VG, Schulman LL and Johnson LA (1978) Distribution and morphology of fresh and frozen-thawed sperm in the reproductive tract of gilts after artificial insemination Biology of Reproduction 19 69-76

Robertson L, Wolf DP and Tash JS (1988) Temporal changes in motility parameters related to acrosomal status: identification and characterization of populations of hyperactivated human sperm Biology of Reproduction 39 797-805

Saacke RG (1982) Components of semen quality Journal of Animal Science 55 (Supplement 2) 1-13

Saacke RG and White JM (1972) Semen quality tests and their relationship to fertility Proceedings of the 4th Technical Conference on Artificial Insemination and Reproduction, National Association of Animal Breeders (Chicago) pp 22-27

Smith KD, Rodriguez-Rigau LJ and Steinberger E (1981) The influence of ovulatory dysfunction and timing of insemination on the success of artifical insemination donor (AID) with fresh or cryopreserved semen Fertility and Sterility 36 496-502

Suarez SS, Katz DF and Meizel S (1984) Changes in motility that accompany the acrosome reaction in hyperactivated hamster spermatozoa Gamete Research $10253-265$

Talbot P (1985) Sperm penetration through oocyte investments in mammals American Journal of Anatomy 174 331-346

Ulstein $\mathbf{M}$ (1973) Fertility, motility and penetration in cervical mucus of freezepreserved human spermatozoa Acta Obstetrica et Gynecologica Scandinavica 52 205-210

Woolley DM and Richardson DW (1978) Ultrastructural injury to human spermatozoa after freezing and thawing Journal of Reproduction and Fertility 53 389-394

Yanagimachi R (1981) Mechanisms of fertilization in mammals. In Fertilization and Embryonic Development In Vitro pp 81-182. Eds L Mastroianni and JD Biggers. Plenum Press, New York

Yanagimachi R (1988) Mammalian fertilization. In The Physiology of Reproduction pp 135-185 Eds E Knobil and J Neill. Raven Press, New York

Zinaman M, Drobnis EZ, Morales P, Brazil CK, Kiel M, Cross NL, Hanson FW and Overstreet JW (1989) The physiology of sperm recovered from the human cervix: acrosomal status and response to inducers of the acrosome reaction Biology of Reproduction 41 790-797 